\title{
Work-family life courses and psychological distress: Evidence from three British birth cohort studies
}

\author{
Anne McMunn ${ }^{\mathrm{a}, *}$, Rebecca Lacey ${ }^{\mathrm{a}}$, Diana Worts ${ }^{\mathrm{b}}$, Diana Kuh ${ }^{\mathrm{c}}$, Peggy McDonough ${ }^{\mathrm{b}}$, \\ Amanda Sacker ${ }^{\text {a }}$ \\ ${ }^{a}$ Department of Epidemiology \& Public Health, University College London, 1-19 Torrington Place, London, WC1E 7HB, UK \\ ${ }^{\mathrm{b}}$ Dalla Lana School of Public Health, University of Toronto, Health Sciences Building, 155 College Street, 6th Floor, Toronto, ON, M5T 3M7, Canada \\ ${ }^{\mathrm{c}}$ MRC Unit for Lifelong Health and Ageing, University College London, 33 Bedford Place, London, WC1B 5JU, UK
}

\section{A R T I C L E I N F O}

\section{Keywords:}

Work

Family

Gender

Psychological distress

Lifecourse

British birth cohort studies

\begin{abstract}
A B S T R A C T
This study uses multi-channel sequence analysis to characterize work-family life course types between the ages of 16 and 42, and multivariable logistic regression to examine their association with psychological distress at age $42 / 43$ for men and women in three nationally-representative British birth cohorts born in $1946(\mathrm{~N}=2,858)$, $1958(\mathrm{~N}=9,140)$, and $1970(\mathrm{~N}=7,095)$. We hypothesised that work-family life courses characterized by weaker links to employment and earlier transitions to partnerships and parenthood would be associated with a greater probability of psychological distress at age 42, and that this association would be become more pronounced across cohorts. Levels of psychological distress were higher amongst men and women with weaker long-term ties to employment, although these were largely explained by early life factors. Teen mothers had higher levels of psychological distress in the two later-born cohorts, and this remained unexplained in adjusted models for the 1970 cohort.
\end{abstract}

\section{Introduction}

Many countries have seen dramatic changes over the past forty years in the nature of work, family and the normative gender divisions between them (public, paid labour for men, unpaid caring and domestic labour for women) steadily eroding (Kan et al., 2011; Perelli-Harris et al., 2017; Office for National Statistics, 2013). This potential move towards 'gender convergence' may have implications for the mental health of men and women. Stable employment and partnership have both consistently been shown to be health enhancing (Blomgren et al., 2012; Brockmann \& Klein, 2004); however, employment and family life influence one another, particularly for women (Argyrous et al., 2017; McMunn et al., 2019; Schober, 2013). Entry into parenthood has traditionally limited women's participation in employment through labour market exits and reduced working hours. Gender differences in the interplay between employment and family life may lead to gender differences in their impact on mental health and suggest the importance of considering paid employment and family life together. For example, the health benefits of marriage have traditionally been shown to be greater for men than women (Clouston et al., 2014; Guralnik et al., 2009; Lund et al., 2014; Pachana et al., 2011; Woods et al., 2019) as the transition to marriage and parenthood have tended to trigger an increase in unpaid care work for women and not men (Argyrous et al., 2017; Schober, 2013). On the other hand, as traditional gender norms and expectations attached to social institutions steadily erode (Beck-Gernsheim, 2002; Giddens, 1992) and partnerships become more egalitarian (England \& Kilbourne, 1990; Folbre, 2008), we may expect to see cohort changes in the impact of partnership and the interchange between employment and family life on mental health, and the gender differences between them, and evidence in more recent cohorts suggests this may be the case (Williams, 2003).

In order to understand how work and family life influence mental health, a life course approach is required. First, to establish the timing of events, such as whether the onset of psychological distress occurs subsequent to, rather than prior to, key life course transitions, is a fundamental starting point for thinking about causal processes between the two. For example, if those who combine employment with partnership and parenthood are healthier, is this a result of combining these activities, or is the association the result of healthier young men and women being more likely to enter the work force, form partnerships and have

\footnotetext{
* Corresponding author.

E-mail address: a.mcmunn@ucl.ac.uk (A. McMunn).
} 
children, or a combination of bi-directional processes? Few studies have explicitly investigated potential selection effects in relation to work or family life courses and mental health, and those that have suggest that the mental health advantage of combining paid employment with stable partnership is not explained by health selection into employment and partnership (Di Gessa, Corna, Price, \& Glaser., 2020; Frech \& Damaske, 2012; McMunn, Bartley, Hardy, \& Kuh, 2006). In addition, a life course approach allows for the characterisation of multiple states and transitions over time, such as the duration of employment spells or the accumulation of periods of unemployment alongside family transitions such as entry into parenthood or divorce which may act as potential triggers for employment transitions or health events. A life course approach also recognises the role of early life factors in establishing trajectories of advantage and disadvantage as highlighted by the Cumulative Advantage/Disadvantage (CAD) framework (Dannefer, 2003; Kendig \& Nazroo, 2016; McDonough et al., 2015; O'Rand, 2009), and setting individuals onto psychological, behavioural and biological pathways linking social and material circumstances and health (Bartley, 2004). We know, for example, that childhood socioeconomic circumstances are strongly related to educational attainment, which in turn strongly influences employment trajectories (Lacey et al., 2013; Schoon, 2009; Worts et al., 2013; Xue et al., 2006). Thus, this study takes a life course approach to understanding how the combined effect of work and family over the life course influences mental health in mid-life for men and women in three distinct British birth cohorts born in 1946, 1958, and 1970.

\section{Background}

\subsection{Work, family and mental health: pathways and mechanisms}

There is a large body of evidence showing that stable employment and partnership, as well as later transitions to parenthood - when considered separately from one another - are health enhancing for both men and women, and are associated with a lower risk of mortality (Blomgren et al., 2012; Brockmann \& Klein, 2004; Chandola \& Zhang, 2018; Einiö et al., 2015; Flint et al., 2013; Hardy et al., 2009; Hughes et al., 2017; Hughes et al., 2014; Lacey, Kumari, Sacker, \& McMunn, 2017; Lucas, 2005). While the mental health benefits of employment vary by job quality (Chandola \& Zhang, 2018; Henseke, 2018), there are a variety of pathways through which participation in employment per se fosters positive mental health. Employment offers the ability to independently generate one's own financial resources, access to a wider social network from which to potentially draw support and increased social contact, the imposition of a time structure to the day, self-esteem derived from participating in a collective purpose, as well as identity and status (Jahoda, 1982; Paul \& Batinic, 2009). However, work and family life are interwoven with differing consequences for men and women. As with job quality, the mental health benefits of marriage and partnership are likely to depend on the quality of the relationship (Robles et al., 2014); however, stable partnership per se is generally linked with positive mental health (Yan et al., 2011). This may operate through the provision of close personal support, financial economies of scale, or improved health behaviours (Waite \& Maggie, 2001). For the generations of women born in the first part of the 20th Century in particular, marriage represented a source of increased financial security; however, it also often signified a barrier to employment even before entry to parenthood (Xue et al., 2006). Traditional patriarchal gender norms structure rules and resources such that entry into parenthood has traditionally restricted women's opportunities to participate in employment, thereby limiting women's agency in accessing the potentially health-enhancing (as well as health damaging) aspects of employment (McMunn, Melanie, \& Diana, 2006). As mothers increasingly sought to combine employment with parenthood over the latter decades of the Twentieth Century, two opposing models predicted the potential impact on their mental health. The role strain theory, which states that social actors continually seeking to reduce the demands of their many, and sometimes conflicting, roles was used to suggest that combining the responsibilities of paid employment with those of family life would be detrimental for mothers' mental health (Goode, 1960), while role enhancement theorists (Marks, 1977) emphasised the health enhancing properties of participation in all socially valued activities, such as marriage, parenthood and employment. Some early investigators hypothesised a process of role trade-off in which emotional and material resources provided by one role were used to meet the demands of another (Thoits, 1991; Verbrugge, 1983), a precursor to the more recent spillover model which posits that stressful exposures from home or work sometimes spillover from one environment to another potentially leading to role conflict and negative health outcomes (Grzywacz Joseph et al., 2002; Grzywacz Joseph \& Marks, 2000; Kinnunen et al., 2006). Early empirical work typically showed that women who combined employment with marriage and parenthood were healthier than those who did not (for example, Kuntsche et al., 2009; Lahelma et al., 2002; but see Glynn, Maclean, Forte, \& Cohen., 2009); however, the vast majority of these studies were cross-sectional in design, raising the question of health selection as an explanation.

As gender norms have weakened over time, parenthood and partnership place fewer restrictions on women's employment, although evidence suggests that entry to parenthood continues to trigger a reset in gender relations towards more traditional roles amongst couples (Kuhhirt, 2012; McMunn et al., 2019; Schober, 2013). So, while we might expect parenthood to play a weaker role in structuring women's employment across generations, we might also expect the poor mental health of those in life courses characterised by weak labour market attachment to be stronger in more recent generations as these life courses become both less prevalent and less normative. The adoption of roles in the light of normative expectations are likely to be a source of self-conception and self-esteem, and, therefore, crucial in the maintenance of positive mental health (McLeod, 2012; Thoits, 1991). Indeed, while we argue that participation in employment and partnership has health benefits per se, the influence of changing social norms in relation to gender roles, and marriage / partnership may moderate these health benefits through changing expectations and values. For example, for many working-class women born in the early part of the Twentieth Century, full-time homemaking represented emancipation from hours of paid labour on top of hours of domestic labour at home (Roberts, 1995). For women born in the post-war period, strong social norms regarding early entry into marriage and parenthood may have shaped expectations and attitudes such that limited opportunities for employment were outweighed by desires for family formation, at least temporarily (Tinkler et al., 2017). For men, change has been slower. While the concept of a 'family wage' for fathers has dissipated (Crieghton, 1999), it remains the case that men do not reduce their employment hours in response to parenthood, at least through pre-Millennial cohorts (Harrington et al., 2017), and an inability to participate in employment, such as through unemployment, remains particularly detrimental to men's mental health (Artazcoz et al., 2004; Strandh et al., 2012). The centrality of employment to men's lives may not have changed, but the nature of their partnerships and the resources men derive from them may have. As partnerships become more egalitarian, the greater mental health benefits of partnership for men, compared with women, may be shifting such that stable partnership is becoming more equally health enhancing for men and women (Williams, 2003).

\subsection{Work, family and mental health: taking a life course approach}

There is a long history of studying the impact on mental health of combining employment with married motherhood amongst women (Klumb \& Lampert, 2004). As more longitudinal data became available, studies began to examine associations between work and family and health longitudinally. at two or three time points (Hewitt et al., 2006; Janzen \& Muhajarine, 2003; Johansson et al., 2007; Klumb \& Lampert, 
2004;) but often did not take early health into account, with some exceptions (Frech \& Damaske, 2012; Leupp, 2017; McMunn, Bartley et al., 2006; Nordenmark, 2004). Longitudinal studies using more than two waves of data have consistently found health benefits of continuous employment for women and men where men have been included (Frech \& Damaske, 2012; Leupp, 2017; McMunn, Bartley et al., 2006; Tosi \& Grundy, 2019).

Increasingly, detailed life course data are enabling the consideration of long-term work and family biographies in combination, allowing investigation of the duration of different states in each of these domains, the timing of transitions between states, and direction of associations between work, family and health states and transitions. Sequence analysis is a data reduction technique which uses whole life courses as the unit of analysis (Barban \& Billari, 2012). More recently, life course studies of employment and health have adopted sequence analysis to characterise entire employment life courses - timing of transitions and lengths of spells in combination - in relation to health outcomes in both the English Longitudinal Study of Ageing (ELSA) and its sister study in Europe, the Survey of Health and Retirement in Europe (SHARE). Both found that mothers who took a break from work and returned full-time were less likely to report poor health (in ELSA) or reported better quality of life (in SHARE) than women who maintained full-time employment (Stone et al., 2015; Wahrendorf, 2015). In SHARE, long-term homemakers also reported lower quality of life than those who took time out from work for parenting and returned full-time (Wahrendorf, 2015). The work in ELSA was recently updated in an investigation of differences in somatic health, mental health and quality of life trajectories by employment sequences (Di Gessa et al., 2020). Similar to the earlier study in ELSA, women who took medium length breaks from employment (about eight years on average) and returned to full-time employment ended up with better somatic health and quality of life in retirement compared with women who maintained continuous employment. This study also included men and found that men with weak long-term ties to employment also had worse somatic health and quality of life than men who maintained continuous employment, although the difference between groups decreased somewhat over time. Employment histories were not associated with depression for men or women. These studies provide a detailed characterisation of life course employment patterns but are not able to distinguish how associations between these patterns and mental health might vary depending on the family circumstances.

In recognition that family life continues to restrict women's participation in employment through work breaks and reduced hours, a handful of studies have extended work using single channel sequence analysis to characterise employment life courses to using multi-channel sequence analysis (MCSA) which allows for the simultaneous characterization of the length, ordering and number of spells, as well as the number and timing of transitions of multiple life course domains together. Nearly all of these studies using MCSA to capture work and family life courses have been restricted to women. Sabbath Erica, Guevara, Glymour, and Berkman. (2015) found that women whose life courses exhibited long periods out of employment died significantly younger than women who maintained stronger ties to employment, and this was equally true for lone and partnered mothers. van Hedel et al. (2016) used MCSA to compare work-family life course associations with health between women in Europe and the United States. They found that, compared with employed married mothers, in the US non-working married mothers were more likely to be obese, in both regions lone mothers were more likely to have heart disease and to smoke, and in Europe single childless working women were also more likely to smoke. Two previous studies investigated work-family life courses and mental health using MCSA and included both women and men. One in a national British birth cohort born in 1946 showed that women with weaker ties to paid work over the long-term had significantly lower life satisfaction at age 60 than women who had combined paid work with stable partnership and parenthood, as did both men and women who had not partnered or had children (Lacey, Stafford, Sacker, \& McMunn, 2016). The other, among West Germans born between 1925 and 1955, found no associations for men, and women who returned to employment full-time after a period of looking after the family full-time, were more likely to be depressed than women who returned to employment part-time (Engels et al., 2019). The authors attribute this finding to higher levels of single mothers in the group of women who returned to employment full-time.

These previous MCSA studies of work-family life courses and health have focused on generations born in the first half of the twentieth century, who entered marriage and parenthood at the youngest and most uniform ages on record in the UK (Kiernan \& Diamond, 1983; Kiernan \& Eldridge, 1987). Thus, these studies do not capture the subsequent social and demographic changes to work and family life experienced by generations born in the second half of the 20th Century. We do not know if associations seen in generations who experienced more traditional gender norms will be the same in cohorts for whom long periods out of employment (for women) and early marriage and parenthood (for both sexes) have become less normative. In addition, very few studies have investigated the health effects of changes in work and family life for men. Nordenmark (2004) found that combining work and family responsibilities was equally associated with better health among men and women in Sweden, but Janzen and Muhajarine (2003) found this only to be the case for older men in Canada. The frequent exclusion of men presupposes that work and family domains are independent for them. While it may still be the case that family life impacts much less on men's employment than women's, there is a growing narrative suggesting millennial men want to be more involved in family life (Harrington et al., 2017). It is crucial that men are included in research in this area going forward in order to document the extent of reductions or continuities in gender disparities. One previous study has used MCSA to investigate cohort differences in work-family life courses and body mass index in both men and women in the UK. It found higher BMI amongst men and women who made earlier transitions to parenthood and had weaker long-term ties to employment, and this association became stronger across cohorts as these biographies became less normative and less prevalent (Lacey, Sacker et al., 2017).

\subsection{The present study}

The current study seeks to compare associations between workfamily life courses and psychological distress in mid-life for men and women across three British birth cohorts. It uses MCSA to simultaneously capture spells, ordering and transitions in employment, partnership and parenthood in both men and women across these cohorts. We examine associations between work-family life course types (LCTs) and psychological symptoms at age 42 (the oldest age at which data were available for the most recent cohort at the time of analysis), independent of early life health and early life and adult social and economic circumstances. Based on previous theoretical and empirical work showing the health benefits of employment for both men and women, and the role of family life in potentially limiting access to employment for women in particular, we hypothesise that (1) work-family life courses characterized by weaker links to employment and earlier transitions to partnership and parenthood will be associated with more psychological symptoms at age 42 (Flint et al., 2013; Hardy et al., 2009; Lacey, Kumari et al., 2017). In addition, we hypothesise that social norms will play a role in the impact of work-family biographies on mental health, with higher levels of psychological distress amongst those who follow biographies which are less normative for their cohort. As a result, long periods spent out of employment may become more strongly associated with poor mental health in later cohorts as this life course becomes both less prevalent and less normative for women. In addition, early entry into partnership and parenthood is strongly normative for those born in the earlier part of the Twentieth Century, but becomes both less normative and less prevalent over time. For these reasons, we hypothesise that (2) the elevated risk of psychological 
distress among those with weak labour force attachment and early family transitions will be more pronounced for women over historical time (that is, across cohorts), reflecting the increasingly non-normative nature of these work-family life courses and their increasing potential to be experienced as restrictive. However, as norms regarding gender roles have changed less for men across the cohorts included in our study (Gustafsson et al., 2019), we hypothesise that (3) men with weak links to employment and partnership have more psychological distress across all three cohorts.

Our study builds on existing research in three key ways. First, we adopt a broader view than previous studies, by considering how combined paid work, partnership and parenthood biographies in combination are associated with adult mental health. Second, we take a longer view than much existing research modelling patterns in employment, partnership and parenthood across a significant period of adulthood and including health and socioeconomic indicators from early life in recognition of the potential for early life circumstances to influence life course trajectories and the accumulation of advantage and disadvantage. Third, we take a contextual view comparing results across both generations and genders, acknowledging that the life course is embedded in and shaped by the social and historical milieu of an individual's lifetime (Elder \& Johnson, 2002).

\section{Data and methods}

\subsection{Data}

This study used three nationally-representative British birth cohorts - the MRC National Survey of Health and Development (NSHD, 1946 cohort) (Wadsworth, Kuh, Richards, \& Hardy., 2006), the National Child Development Study (NCDS, 1958 cohort) (University of London et al., 2008), and the 1970 British Cohort Study (BCS70, 1970 cohort) (University of London et al., 2016). The NSHD is a stratified random sample of all births in Great Britain during a single week of 1946 to married women with husbands in agricultural or non-manual employment and one in four births to women with husbands in manual employment ( $\mathrm{n}=$ 5,362 ) (Wadsworth et al., 2006). The unequal selection probability was taken account of using sampling weights in all analyses. Cohort members were surveyed 15 times prior to age 25 , and at ages $26,31,36,43$, 53 , and 60-64 years in adulthood. The NCDS recruited all babies born in a single week of $1958(\mathrm{n}=17,415)$ (Power \& Elliott, 2005). Cohort members were surveyed at birth, $7,11,16,23,33,42,44,46,50$, and 55 years. The BCS recruited all babies born during one week of 1970 ( $\mathrm{n}=$ 16,571) (Elliott and Shepherd 2006). Cohort members were surveyed at birth, 5, 10, 16, 26, 30, 34, 38, and 42 years. All three cohorts are rich sources of social, economic, health and developmental information. This study used information on each cohort up to age 43 years in the NSHD and 42 years in the NCDS and BCS. Response rates were $87 \%$ of those eligible at age 43 in NSHD, $70 \%$ in the NCDS, and $85 \%$ in the BCS70.

\subsection{Variables}

\subsubsection{Work-family life courses}

Annual work, partnership and parenthood statuses were derived for ages 16-42 years. Work was categorised as full-time employment, parttime ( $\leq 30 \mathrm{~h}$ per week), looking after the home and family, or other not employed (in full-time education or training, unemployed, long-term sick, or other). Partnership status was categorised as married, cohabiting or not living with a partner. Parental status was defined as youngest child in the household $<5$ years, youngest child in the household aged $5-16$ years, or no children in the household/youngest child $>16$ years. These three domains of work, partnerships, and parental status were cross-classified to produce 26 annual work-family state variables (one for each year between ages 16 and 42), each with 36 possible categories (4 employment x 3 partnership x 3 parenthood).

\subsubsection{Psychological distress}

At age 43, NSHD cohort members completed the Psychiatric Symptom Frequency (PSF), which comprises 18 items referring to symptoms of depression and anxiety in the previous year (Lindelow et al., 1997). At age 42, NCDS and BCS participants completed the Malaise Inventory (Rutter, 1970), which comprises a series of binary-coded items (24 in the NCDS and 9 in the BCS) capturing emotional and somatic symptoms. All three scales have been validated for use in general population samples and had high internal consistency (NSHD: $\alpha=0.88$; NCDS: $\alpha=0.83$, BCS: $\alpha=0.76)$. In order to produce comparable measures, we dichotomised the total scores on each scale to compare the top quintile (most symptoms) with those not in the top quintile. We additionally conducted sensitivity analyses including cohort members with self-reported diagnosed psychological conditions, such as depression and anxiety, in the top quintile, but this did not change our results.

\subsubsection{Covariates}

Covariates included in analyses were conceptualised as early life selection factors, confounders, or mediators. Early life selection factors are socioeconomic position in childhood, prior physical and emotional health, and educational attainment. Socioeconomic position in childhood was measured by father's social class (Registrar General's Social Class (RGSC)), categorised as I (professional), II (managerial and technical), IIINM (skilled non-manual), IIIM (skilled manual), IV (semiskilled manual) or V (unskilled). Father's RGSC was taken when cohort members were age 4 in the NSHD, age 7 in the NCDS, and age 5 in the BCS, and completed with information from subsequent childhood sweeps where this information was missing. (Mothers' occupational class was not collected, reflecting the strong gender norms governing the labour market participation of mothers with young children for the parents of these cohorts). Educational attainment was the highest qualification achieved by early adulthood (age 26 in the NSHD and BCS, and age 23 in the NCDS). The variable was categorised as no qualifications, Ordinary-level (O-level) equivalent, Advanced-level (A-level) equivalent, or degree or higher qualification. The presence of health problems was assessed by medical officers when cohort members were age 16 in the NCDS and BCS, and age 15 in the NSHD. Prior emotional health was measured using Rutter's behaviour scale A (mother-reported) in the NCDS and BCS at age 16. In the NSHD a pre-cursor to Rutter's scale with broadly comparable items was given at age 15. All three scales were subject to factor analysis, and latent variables indicating internalizing and externalizing disorders derived. These were subsequently categorised as absent, mild, or severe, based on agreed cutpoints (Richards \& Abbott, 2009). The presence of a limiting longstanding illness in adulthood (age 43 in the NSHD and age 42 in the NCDS and BCS) was included in this step although it may act as a mediator between work-family LCTs and psychological distress.

Work and support-related mediators included indicators of work quality, paid work demands, job satisfaction, financial hardship, emotional support, and adult occupational class. All work and supportrelated mediating variables were assessed at age 43 in the NSHD and age 42 in the NCDS and BCS. Binary self-rated job security was used as an indicator of work quality. A binary self-report of the physical effort that cohort members' jobs entailed was used to indicate paid work demands. Job satisfaction was a 5-point Likert scale from very dissatisfied to very satisfied. Financial hardship was categorised as managing comfortably, fairly well, or finding it hard to manage. Emotional support was based on the availability of a friend or family member to turn to if help or support was needed. Finally, adult occupational class was indicated by the RGSC (categorised as above) of the cohort member or their partner, whichever was higher, adopting a gender neutral approach while recognising that individual-level occupational class may not capture access to status and resources amongst generations of women whose employment histories are more fractured and who may have experienced occupational downgrading following entry to parenthood (Dex, Ward, \& Joshi., 2006; Harkness, Borkowska, \& Pelikh., 2019; Krieger et al., 
1999).

\subsection{Statistical analyses}

\subsubsection{Characterising work-family LCTs}

MCSA was used to group individuals' work-family life courses in each cohort using the combined work-family variables described above. MCSA uses whole work-family life courses as the unit of analysis (Barban \& Billari, 2012) and compares each sequence to all others in the dataset and measures of the distinctness (or similarity) of individuals' biographical sequences (Abbot \& Tsay, 2000) using distance measures representing the "cost" (reflecting the number of substitutions and insertions or deletions needed) of converting one to another (MacIndoe \& Abbott, 2004). Here we used a conceptual MCSA approach in which distance scores were derived relative to a set of reference sequences, or "ideal-type" sequences (Gauthier et al., 2013; Pollock, 2007; Wiggins et al., 2007). This entailed developing a set of ideal-typical work-family reference life course sequences that described various pathways three cohorts might have traced in each of the three domains over the ages 16-42. The first two authors of this paper each independently designed a set of ideal types based on existing theory and research concerning key patterns - both past and present - in work and family arrangements (Crompton, 2006, Ferri et al., 2003). The separately-developed typologies were then compared with one another and were found to overlap substantially and a common set of 12 reference sequences was agreed upon. Twelve groups were required to capture variation across men and women in all three cohorts while maintaining identical groups across gender and cohorts in order to make comparisons. See Appendix A for chronographs of the work, partnership and parenthood patterns for each LCT; further detailed description of the LCTs can be found in McMunn et al. (2015). Four work-family LCTs characterized by part-time employment or taking time off work to look after the family contained too few men in any of the three cohorts to produce reliable estimates. These groups are therefore only considered in the analyses of women.

\subsubsection{Missing data}

This study accounted for missing data in two stages. First, missing information on work, partnerships and children in the household was imputed using an approach developed by Halpin (2013) prior to running the sequence analysis. All three domains were included in the imputation of all others. Twenty imputed datasets were created. The sequence analysis and the allocation of participants to their closest model biography were conducted separately on each of the 20 imputed datasets. Then, prior to running the regression analyses, missing information was accounted for using multiple imputation by chained equations in the 20 datasets. We employed the method of multiple imputation followed by deletion, whereby information on all analysis variables was imputed for all participants but only those with observed information on psychological distress at age 42/43 were retained for analysis (Von Hippel, 2007). This resulted in final analytical samples of 2,858 in the NSHD, 9 , 140 in the NCDS, and 7,095 in the BCS. Appendix B shows the distribution of analysis variables in imputed and complete case data for men and women in each cohort.

\subsubsection{Regression analyses}

Associations between work-family LCTs and psychological distress in mid-life were tested using multivariable logistic regression. First, unadjusted associations were estimated. Second, confounders and early life selection factors were included in the models. Finally, mediators were additionally included. Regression models used the 'work, later family' LCT as the reference category; however, because of the non-normative nature of this group in the earliest cohort, particularly for women, the appropriateness of its use as the reference category may be questionable, Thus, we converted the estimates from our models to predicted probabilities, along with confidence intervals, for all categories. All analyses were stratified by gender and conducted in Stata version 13 .

\section{Results}

The distribution of work-family LCTs of men and women by cohort have been shown previously (McMunn et al., 2015) and are shown again in Table 1. The vast majority of men in all three cohorts were in one of the six work-family types characterized by stable participation in full-time employment (98\% in the 1946 and 1958 cohorts and $96 \%$ in the 1970 cohort). The percentage of men in the LCT capturing early family formation ('Work, Early Family') decreased dramatically across cohorts, from $47 \%$ in the 1946 cohort to $32 \%$ in the 1958 cohort and only $14 \%$ in the 1970 birth cohort. The proportion of women in one of the six types characterized by continuous full-time employment increased steadily from $31 \%$ in the 1946 cohort, to $47 \%$ in the 1958 , and $61 \%$ in the 1970 cohort. The percentage of women in the LCT characterized by long-term full-time domestic work ('No Paid Work, Early Family') dropped fairly substantially, between the 1946 and 1958 cohorts (13\% and $4 \%$, respectively), then down to 3\% in the 1970 cohort, while membership of the 'Early Family, Work Break' type was lower amongst women in the 1970 cohort $(7 \%)$ than in the two earlier-born cohorts (16-18\%).

Table 1 shows increases across cohorts in the percentage of both women and men in the LCT characterized by long-term cohabitation ('Work, Cohabitation, Later Family'), with a particularly large upturn to $13 \%$ of men and $11 \%$ of women in the 1970 cohort (compared with $2 \%$ and $1 \%$ respectively in the 1946 cohort and $7 \%$ and $5 \%$ respectively in the 1958 cohort). Perhaps the most striking finding was the high preponderance of both men and women in the 1970 cohort in the LCT characterized by minimal or no family ties by age 42 combined with continuous full-time employment (the 'Work, No Family' type). Over a quarter of men and nearly a fifth of women in the 1970 cohort belonged to this LCT compared with $11 \%$ and $5 \%$, respectively, of men and women in the 1946 cohort and $13 \%$ and $10 \%$, respectively, of men and women in the 1958 cohort. Appendix C shows the distribution for all covariates by work-family LCTs for men and women in each cohort.

\subsection{Work-family LCTs and psychological distress amongst men}

In the cohort born in 1946, men in the 'Unstable work, no family' and

Table 1

Distribution of work-family life course types by birth cohort and gender.

\begin{tabular}{|c|c|c|c|c|c|c|}
\hline & \multicolumn{2}{|c|}{$\begin{array}{l}1946 \text { birth } \\
\text { cohort }(\mathrm{N}= \\
2,858)\end{array}$} & \multicolumn{2}{|c|}{$\begin{array}{l}1958 \text { birth } \\
\text { cohort }(\mathrm{N}= \\
9,140)\end{array}$} & \multicolumn{2}{|c|}{$\begin{array}{l}1970 \text { birth } \\
\text { cohort }(\mathrm{N}= \\
7,095)\end{array}$} \\
\hline & $\begin{array}{l}\text { Men } \\
\%\end{array}$ & $\begin{array}{l}\text { Women } \\
\%\end{array}$ & $\begin{array}{l}\text { Men } \\
\%\end{array}$ & $\begin{array}{l}\text { Women } \\
\%\end{array}$ & $\begin{array}{l}\text { Men } \\
\%\end{array}$ & $\begin{array}{l}\text { Women } \\
\%\end{array}$ \\
\hline Work, later family & 26.4 & 2.7 & 33.7 & 8.5 & 30.0 & 11.8 \\
\hline $\begin{array}{l}\text { Work, cohabitation, } \\
\text { later family }\end{array}$ & 2.2 & 1.1 & 6.8 & 5.1 & 13.1 & 11.0 \\
\hline $\begin{array}{l}\text { Work, marriage, non- } \\
\text { parent }\end{array}$ & 9.7 & 6.6 & 7.9 & 8.9 & 9.5 & 9.2 \\
\hline Work, early family & 47.1 & 15.0 & 31.8 & 11.8 & 14.4 & 6.5 \\
\hline Later family, work break & 0.5 & 12.6 & 0.2 & 13.1 & 0.5 & 12.5 \\
\hline Work, no family & 11.4 & 4.7 & 12.8 & 9.7 & 26.4 & 18.9 \\
\hline Early family, work break & 0.01 & 17.6 & 0.1 & 16.2 & 0.1 & 6.6 \\
\hline $\begin{array}{l}\text { Part-time work, early } \\
\text { family }\end{array}$ & 0.4 & 23.0 & 0.3 & 17.9 & 0.2 & 13.0 \\
\hline $\begin{array}{l}\text { No paid work, early } \\
\text { family }\end{array}$ & 0.01 & 12.9 & 0.1 & 4.1 & 0.2 & 2.9 \\
\hline Lone parent, divorced* & 1.0 & 0.6 & 4.4 & 2.8 & 2.9 & 3.2 \\
\hline Teen parent* & 0.5 & 2.9 & 0.9 & 1.5 & 0.4 & 2.7 \\
\hline $\begin{array}{l}\text { Unstable work, no } \\
\text { family }\end{array}$ & 0.8 & 0.4 & 1.1 & 0.6 & 2.6 & 1.7 \\
\hline
\end{tabular}

"The 'Teen parent' and 'Lone parent, divorced' labels only refer to family roles to emphasise the defining features of these groups. Their work patterns are characterised by full-time employment, although after a period of full-time domestic work in their early twenties for teen parents. See McMunn et al., 2015 for detailed ideal type specifications. 
the 'Teen parent' LCTs had a much higher probability of psychological distress (24\%) than men in other groups, but no differences between work-family LCTs were significant. In the cohort born in 1958, men in the 'Unstable work, no family' group were more likely to be psychologically distressed (33\%) than men in other groups in unadjusted models (except the 'Lone parent, divorced' group with whom confidence intervals just overlap). This association was reduced by a third with the inclusion of early life factors (particularly internalizing problems) and longstanding illness in adulthood. Contrary to our hypothesis, men in the 'Teen parent' LCT had the lowest probability of psychological distress amongst those born in 1958 at 5\%, although wide confidence intervals mean their risk was only significantly different from those in the 'Unstable work, no family' group (marginally so with respect to the 'Lone parent, divorced' LCT).

Similarly, in the cohort born in 1970, men in the 'Unstable work, no family' group had a much higher probability of psychological distress (44\%) than men in other groups in the unadjusted model. As with men in the 1958 cohort, the inclusion of early life factors (particularly internalizing problems) and limiting longstanding illness in adulthood attenuated this association by a third, but the probability of psychological distress remained higher $(28 \%)$ than for men in every other group. The high probability of psychological distress amongst men in the 'Unstable work, no family' group was further attenuated (to $20 \%$ ) by the inclusion of mediators in the model (Table 2).

\subsection{Work-family LCTs and psychological distress amongst women}

Amongst those born in 1946, women in the 'Work, later family' LCT had the highest probability of psychological distress ( $40 \%$ ) while those in the 'No paid work, early family' LCT had the second highest probability of psychological distress at $30 \%$. Somewhat surprisingly given the strong norms regarding marriage for the 1946 cohort, the very small number of women in the latter LCT had the lowest likelihood of psychological distress (3\%). This probability was lower than that for women in the majority of other LCTs in this cohort, even in adjusted models.

In the 1958 birth cohort, women in the 'Teen parent' and 'No paid work, early family' LCTs had the highest probability of psychological distress (47 \% and $32 \%$ respectively) in the unadjusted models. Both levels were significantly higher than those for women in every other LCT except 'Unstable work, no family', whose probability was $35 \%$, but who numbered only 28 in this cohort. The high probability of psychological distress amongst women in the 'Teen parent' and 'No paid work, early family' groups was attenuated by about $30 \%$ with the inclusion of early life factors, own education and adult longstanding illness (all contributing to the attenuation). Once early life factors were included, the risk was no longer elevated for women in the 'No paid work, early family' group, but amongst women in the 'Teen parent' group psychological distress remained higher than for women in groups characterized by later or no parenthood. Although the probability of psychological distress remained highest for 'Teen parents' once mediators were added (27\%), there were no longer any statistically significant differences between groups in the fully-adjusted models. Women in the 'Lone parent, divorced' LCT in the 1958 cohort also had a relatively high probability of psychological distress (27 \%) in unadjusted models. This was only slightly attenuated with the inclusion of early life factors and adult chronic illness, but was further attenuated once potential mediators were included in the model.

In the cohort born in 1970, again, women in the 'Teen parent' and the 'Unstable work, no family' LCTs were much more likely to have

Table 2

Predicted probabilities for being in the top quintile of mental health symptoms by work-family life course type ${ }^{\mathrm{a}}$ and birth cohort amongst men.

\begin{tabular}{|c|c|c|c|c|c|c|}
\hline & \multicolumn{2}{|c|}{1946 birth cohort } & \multicolumn{2}{|c|}{1958 birth cohort } & \multicolumn{2}{|c|}{1970 birth cohort } \\
\hline & Predicted prob & $95 \% \mathrm{CI}$ & Predicted prob & $95 \% \mathrm{CI}$ & Predicted prob & $95 \% \mathrm{CI}$ \\
\hline \multicolumn{7}{|l|}{ Model 1 - crude association } \\
\hline Work, later family & 0.10 & $0.07,0.14$ & 0.12 & $0.11,0.14$ & 0.13 & $0.11,0.15$ \\
\hline Work, marriage, non-parent & 0.12 & $0.06,0.19$ & 0.12 & $0.08,0.15$ & 0.11 & $0.08,0.15$ \\
\hline Work, early family & 0.14 & $0.11,0.17$ & 0.12 & $0.11,0.14$ & 0.14 & $0.11,0.18$ \\
\hline Work, no family & 0.16 & $0.10,0.23$ & 0.13 & $0.10,0.16$ & 0.15 & $0.13,0.18$ \\
\hline Lone parent, divorced & 0.12 & $-0.10,0.34$ & 0.17 & $0.12,0.23$ & 0.13 & $0.06,0.20$ \\
\hline \multicolumn{7}{|c|}{ Model 2 - adjusted for confounders \& early life factors ${ }^{\mathrm{b}}$} \\
\hline Work, later family & 0.10 & $0.07,0.14$ & 0.13 & $0.12,0.15$ & 0.14 & $0.12,0.16$ \\
\hline Work, cohabitation, later family & 0.08 & $-0.04,0.20$ & 0.13 & $0.10,0.17$ & 0.16 & $0.13,0.20$ \\
\hline Work, marriage, non-parent & 0.13 & $0.07,0.20$ & 0.13 & $0.09,0.16$ & 0.12 & $0.08,0.16$ \\
\hline Work, early family & 0.14 & $0.11,0.17$ & 0.12 & $0.10,0.13$ & 0.14 & $0.11,0.18$ \\
\hline Work, no family & 0.14 & $0.09,0.20$ & 0.13 & $0.11,0.16$ & 0.15 & $0.12,0.17$ \\
\hline Work, later family & 0.12 & $0.08,0.15$ & 0.13 & $0.12,0.15$ & 0.15 & $0.13,0.17$ \\
\hline Work, cohabitation, later family & 0.09 & $-0.03,0.21$ & 0.12 & $0.09,0.16$ & 0.16 & $0.12,0.19$ \\
\hline Work, marriage, non-parent & 0.13 & $0.07,0.20$ & 0.14 & $0.10,0.17$ & 0.13 & $0.09,0.16$ \\
\hline Work, early family & 0.14 & $0.12,0.17$ & 0.12 & $0.10,0.14$ & 0.16 & $0.13,0.20$ \\
\hline Work, no family & 0.14 & $0.09,0.19$ & 0.13 & $0.10,0.16$ & 0.14 & $0.12,0.16$ \\
\hline Lone parent, divorced & 0.12 & $-0.02,0.25$ & 0.14 & $0.10,0.19$ & 0.11 & $0.05,0.16$ \\
\hline Teen parent & 0.28 & $-0.17,0.73$ & 0.05 & $-0.01,0.11$ & 0.09 & $-0.03,0.22$ \\
\hline Unstable work, no family & 0.03 & $-0.04,0.10$ & 0.19 & $0.09,0.28$ & 0.20 & $0.13,0.27$ \\
\hline
\end{tabular}

${ }^{\text {a }}$ Results for 'Later family, work break', 'Early family, work break', 'Part-time work, early family' and 'No paid work, early family' are not shown for men as Ns are too small to provide reliable estimates.

b Adjusted for father's social class in childhood, highest educational qualification, health and behavioural difficulties in adolescence, adult limiting longstanding illness.

${ }^{c}$ Further adjusted for job security, paid work demands, job satisfaction, financial hardship, emotional support and household social class. 
psychological distress at age 42 than women in the other work-family LCTs (42\% and $41 \%$ respectively). Women in the 'No paid work, early family' LCT had the third highest probability of psychological distress in this cohort (24\%). The inclusion of early life factors, educational attainment and adult limiting longstanding illness attenuated the high probability of psychological distress for the 'Teen parent' group by a quarter and the 'Unstable work, no family' group by $30 \%$. Women in the 'Teen parent' group remained more likely than those in nearly all other groups to be psychologically distressed. Further adjustment for mediating factors attenuated these associations very little (most attenuation was due to the inclusion of emotional support and financial hardship). Again, perhaps surprisingly, women born in 1970 in the 'Lone parent, divorced' LCT had the lowest probability of psychological distress (13\%) and this remained in adjusted models (Table 3).

\section{Discussion}

By taking a life course approach this study has contributed to our understanding of how mental health in mid-life is associated with workfamily biographies in three ways: the use of multi-channel sequence analysis has allowed for the identification of combinations of work and family life that are linked with psychological distress in mid-life, the importance of cohort differences in links between work-family biographies and psychological distress in mid-life were highlighted, and the importance of early life factors in understanding links between workfamily biographies and psychological distress in mid-life was demonstrated.

We hypothesised that early transitions to family life combined with weak ties to employment would be associated with a greater probability of psychological distress, that this association would strengthen across cohorts for women, and that weak ties to employment and partnership would be linked with greater psychological distress for men consistently across cohorts. We found that biographies characterised by later transitions to family life combined with strong ties to employment were associated with less psychological distress for women in the latter two cohorts, but less so for men and certainly not for women born in 1946. In this earliest born cohort, for whom early transitions to parenthood combined with full-time domestic work were the norm for women, women who combined later parenthood with strong ties to employment had the highest levels of psychological distress. Previous work in similar generations of English women did not find associations with employment life courses and depression, but did find those who maintained continuous employment had worse quality of life and somatic health than women who took a period of time out of employment (about eight

Table 3

Predicted probabilities for being in the top quintile of mental health symptoms by work-family life course type ${ }^{\mathrm{a}}$ and birth cohort amongst women.

\begin{tabular}{|c|c|c|c|c|c|c|}
\hline & \multicolumn{2}{|c|}{1946 birth cohort } & \multicolumn{2}{|c|}{1958 birth cohort } & \multicolumn{2}{|c|}{1970 birth cohort } \\
\hline & Predicted prob & $95 \%$ CI & Predicted prob & $95 \%$ CI & Predicted prob & $95 \%$ CI \\
\hline \multicolumn{7}{|l|}{ Model 1 - crude association } \\
\hline Work, later family & 0.40 & $0.22,0.59$ & 0.15 & $0.11,0.18$ & 0.17 & $0.13,0.20$ \\
\hline Work, cohabitation, later family & 0.03 & $-0.03,0.09$ & 0.21 & $0.16,0.27$ & 0.20 & $0.16,0.24$ \\
\hline Work, marriage, non-parent & 0.26 & $0.15,0.36$ & 0.16 & $0.12,0.19$ & 0.18 & $0.14,0.22$ \\
\hline Work, early family & 0.26 & $0.19,0.34$ & 0.20 & $0.16,0.23$ & 0.18 & $0.13,0.23$ \\
\hline Later family, work break & 0.23 & $0.16,0.30$ & 0.16 & $0.13,0.19$ & 0.16 & $0.12,0.19$ \\
\hline Work, no family & 0.16 & $0.08,0.25$ & 0.15 & $0.11,0.18$ & 0.20 & $0.17,0.23$ \\
\hline Early family, work break & 0.25 & $0.19,0.31$ & 0.21 & $0.18,0.24$ & 0.19 & $0.15,0.24$ \\
\hline Part-time work, early family & 0.21 & $0.16,0.27$ & 0.23 & $0.20,0.25$ & 0.17 & $0.14,0.20$ \\
\hline No paid work, early family & 0.30 & $0.22,0.38$ & 0.32 & $0.26,0.39$ & 0.24 & $0.16,0.31$ \\
\hline Lone parent, divorced & 0.22 & $-0.15,0.58$ & 0.27 & $0.20,0.35$ & 0.13 & $0.07,0.20$ \\
\hline Teen parent & 0.26 & $0.09,0.43$ & 0.47 & $0.35,0.59$ & 0.42 & $0.33,0.52$ \\
\hline Unstable work, no family & 0.17 & $-0.08,0.42$ & 0.35 & $0.16,0.55$ & 0.41 & $0.29,0.53$ \\
\hline \multicolumn{7}{|c|}{ Model 2 - adjusted for confounders \& early life factors ${ }^{a}$} \\
\hline Work, later family & 0.40 & $0.22,0.58$ & 0.18 & $0.14,0.22$ & 0.19 & $0.15,0.23$ \\
\hline Work, cohabitation, later family & 0.02 & $-0.03,0.08$ & 0.21 & $0.16,0.26$ & 0.20 & $0.16,0.24$ \\
\hline Work, marriage, non-parent & 0.26 & $0.15,0.36$ & 0.18 & $0.14,0.21$ & 0.18 & $0.14,0.23$ \\
\hline Work, early family & 0.26 & $0.19,0.34$ & 0.18 & $0.15,0.22$ & 0.19 & $0.14,0.23$ \\
\hline Later family, work break & 0.24 & $0.17,0.30$ & 0.18 & $0.15,0.21$ & 0.16 & $0.13,0.19$ \\
\hline Work, no family & 0.17 & $0.08,0.26$ & 0.17 & $0.13,0.20$ & 0.21 & $0.18,0.24$ \\
\hline Early family, work break & 0.26 & $0.19,0.32$ & 0.21 & $0.18,0.24$ & 0.18 & $0.13,0.22$ \\
\hline Part-time work, early family & 0.23 & $0.17,0.28$ & 0.22 & $0.19,0.25$ & 0.17 & $0.14,0.21$ \\
\hline No paid work, early family & 0.27 & $0.20,0.35$ & 0.23 & $0.17,0.28$ & 0.19 & $0.12,0.26$ \\
\hline Lone parent, divorced & 0.17 & $-0.17,0.52$ & 0.25 & $0.18,0.33$ & 0.14 & $0.07,0.20$ \\
\hline Teen parent & 0.24 & $0.08,0.41$ & 0.33 & $0.23,0.44$ & 0.32 & $0.24,0.41$ \\
\hline Unstable work, no family & 0.12 & $-0.06,0.30$ & 0.28 & $0.11,0.44$ & 0.29 & $0.19,0.40$ \\
\hline \multicolumn{7}{|l|}{ Model 3 - + adjusted for mediators ${ }^{\mathrm{b}}$} \\
\hline Work, later family & 0.40 & $0.23,0.57$ & 0.18 & $0.15,0.22$ & 0.20 & $0.16,0.24$ \\
\hline Work, cohabitation, later family & 0.03 & $-0.03,0.08$ & 0.20 & $0.15,0.24$ & 0.21 & $0.17,0.25$ \\
\hline Work, marriage, non-parent & 0.31 & $0.20,0.41$ & 0.20 & $0.17,0.24$ & 0.20 & $0.16,0.24$ \\
\hline Work, early family & 0.28 & $0.20,0.36$ & 0.20 & $0.17,0.23$ & 0.20 & $0.15,0.24$ \\
\hline Later family, work break & 0.22 & $0.16,0.28$ & 0.17 & $0.14,0.20$ & 0.16 & $0.13,0.19$ \\
\hline Work, no family & 0.18 & $0.09,0.28$ & 0.17 & $0.14,0.21$ & 0.20 & $0.17,0.23$ \\
\hline Early family, work break & 0.25 & $0.19,0.32$ & 0.21 & $0.18,0.24$ & 0.18 & $0.14,0.22$ \\
\hline Part-time work, early family & 0.22 & $0.17,0.28$ & 0.22 & $0.20,0.25$ & 0.18 & $0.15,0.21$ \\
\hline No paid work, early family & 0.24 & $0.17,0.32$ & 0.21 & $0.16,0.26$ & 0.16 & $0.10,0.23$ \\
\hline Lone parent, divorced & 0.17 & $-0.19,0.53$ & 0.21 & $0.15,0.27$ & 0.12 & $0.07,0.18$ \\
\hline Teen parent & 0.28 & $0.11,0.46$ & 0.27 & $0.18,0.35$ & 0.29 & $0.20,0.37$ \\
\hline Unstable work, no family & 0.09 & $-0.06,0.25$ & 0.22 & $0.08,0.37$ & 0.27 & $0.17,0.37$ \\
\hline
\end{tabular}

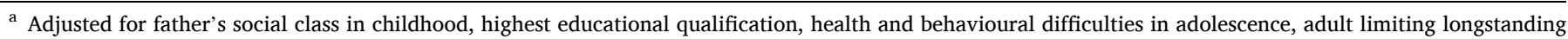
illness.

${ }^{\mathrm{b}}$ Further adjusted for job security, paid work demands, job satisfaction, financial hardship, emotional support and household social class. 
years on average) for family care (Di Gessa et al., 2020).

Women who combined early parenthood with full-time domestic work also had a relatively high probability of psychological distress in mid-life in all three cohorts which is generally in line with previous work showing worse mental health and wellbeing in mid-life amongst longterm full-time homemakers compared with those who had stronger ties to employment (Frech \& Damaske, 2012; Leupp, 2017; McMunn, Bartley et al., 2006; Lacey, Stafford et al., 2016; Tosi \& Grundy, 2019). The relative within-cohort difference in the probability of psychological distress amongst women spending long periods out of employment to look after the family full-time was particularly marked for women born in 1958. This may reflect rapid changes in norms and behaviour in relation to women's employment in the twelve years between the 1946 and 1958 cohorts. Drop-off in women's membership of the 'No paid work, early family' LCT - characterised by spending most if not all of the adult life course to age 42 out of paid work looking after home and family full-time - between the 1946 and 1958 cohorts was the most dramatic change in both absolute and relative terms of all the changes across the three cohorts and two genders, from $13 \%$ to $4 \%$. The median age of return to work after the birth of a first child dropped from six years for women in the 1946 cohort to two in the 1958 (Dex et al., 2006). We also know that women in the 1958 cohort were much more likely than those in the 1946 to obtain degree or higher qualifications (Ferri et al., 2003) and in the 1958 cohort these highly educated women tended not to take time out of employment after childbearing, but rather remained continuously employed and returned to work after taking maternity leave, which was not the case for mothers with degree-level qualifications in the 1946 cohort, on average (Dex et al., 2006). In addition, attitudes supporting the traditional male breadwinner model have steadily declined over the past forty years (Huchet-Bodet et al., 2019; Scott, 2006). These patterns and differences suggest that, while spending a majority of adulthood out of employment was associated with worse mental health to some extent across cohorts, the nature of this life course pattern in terms of its prevalence, social acceptability and socioeconomic composition changed dramatically over time. Our models also show that much of the increased likelihood of poor psychological health of this group in mid-life in the 1958 cohort was explained by physical health in mid-life which may be mediating some of the association seen with psychological distress, but is also a further indication of the disadvantaged composition of this group. This is in line with previous work linking poor physical health with life courses characterised by weak long-term ties to employment amongst women in terms of mortality (Sabbath Erica et al., 2015), obesity (van Hedel et al., 2016; Lacey, Sacker et al., 2017), inflammation (Lacey, Sacker et al., 2016), and self-reports of physical health (Tosi \& Grundy, 2019).

For women in the two later-born cohorts, age of entry into parenthood emerged as being particularly important. Life course biographies which included later transitions to parenthood had a lower likelihood of psychological distress for women in both later-born cohorts. This is in line with previous evidence suggesting health benefits from delaying parenthood for both women and men (Hardy et al., 2009; Lacey, Kumari et al., 2017; Tosi \& Grundy, 2019). Evidence from the United States has also shown that the health benefits of employment are attenuated for mothers when their children are young (Leupp, 2017). As entry to parenthood continues to impact on women's working lives (Argyrous et al., 2017; McMunn et al., 2019; Schober, 2013), more recent cohorts have increasingly turned to later entry into parenthood as a crucial way of managing this impact, allowing time to establish experience in the labour market prior to becoming a parent. The complementary finding that women in the 1958 and 1970 cohorts who became parents in their teens had the highest likelihood of psychological distress in mid-life is in line with results from similar research in the 1958 cohort showing raised levels of health-related biomarker risk factors associated with exposure to chronic stress for this group (Lacey, Sacker et al., 2016; McMunn et al., 2016). Our results in these two later-born cohorts are also in line with evidence from the United States showing longer-term mental health trajectories to be worse for teenage mothers, but not teenage fathers, compared with non-parent teens (Brooks Biello et al., 2010). One reason for cohort differences in the long-term psychological wellbeing of teen mothers may be the changing nature of this group across these cohorts. Those in our teen parent group in the 1946 cohort were much more likely than teen parents in the later-born cohorts to be married and to enter employment as their children grew older (as shown in the chronographs in Appendix C). Also, teen mothers in the two later-born cohorts were more likely than those in the 1946 cohort to report financial difficulties in mid-life; adjusting for this further attenuated their greater chances of psychological distress, suggesting that the economic disadvantage of teen mothers in later cohorts also had a role to play. Changing social norms across these cohorts are also likely to have played a role in the experience of being a teen parent, with social expectations regarding early entry into parenthood much stronger for the earliest born cohort. Another dramatic cohort difference seen was for divorced lone mothers who had a relatively high probability of poor psychological health for women born in 1958, but the lowest probability of psychological distress for the 1970 cohort. The later cohort's mental health advantage was unexpected as reduced financial circumstances amongst divorced mothers are well-documented (Brewer \& Nandi, 2014) so may be related to shifting social norms around divorce and women's higher levels of human capital in later-born cohorts.

Given the lack of changing gender norms for men compared with those for women across cohorts (Huchet-Bodet et al., 2019; Scott, 2006), we hypothesised that ties to employment and partnership would remain equally important for men's psychological health across cohorts. This hypothesis was supported in that, for men from all three cohorts, and women in the two later-born cohorts, the combination of concurrent weak ties to both employment and family life was associated with higher levels of psychological distress in mid-life. A study of English men and women born in the first half of the Twentieth Century also found worse quality of life and somatic health amongst men who had had weak ties to employment, although there were no associations with depression (Di Gessa et al., 2020). In our study, the strength of this association was not constant across cohorts but increased fairly dramatically across cohorts for both men and women. Psychological distress in this group was entirely explained by work, support and socioeconomic factors for men in the 1946 cohort, but not for men or women in this group in the later born cohorts, perhaps reflecting a greater impact of unemployment on wages in later cohorts (Gregg and Machin, 2013) and other factors not accounted for here.

Adopting a life course approach has shown the importance of early life factors in understanding links between work-family biographies and psychological distress in mid-life. Early life socioeconomic and health indicators and educational attainment explained large portions of the high probability of psychological distress for men and women in high risk biographies. For example, some of the greater distress for teen mothers in the later cohorts seems to have been related to higher levels of psychological distress prior to parenthood, particularly for the cohort born in 1958. Levels of externalizing and internalizing behaviour in the teen years were much higher for teen parents in the later-born cohorts than for teen parents born in 1946 (see Appendix C) for whom early parenthood was much more common. In addition, women in the group characterised by long periods of time spent out of the employment to look after the home in the later-born cohorts had somewhat higher levels of externalizing problems in adolescence, which accounted for some of the increased likelihood of poor mid-life psychological health in this group. Internalizing symptoms in the teen years also explained significant portions of the psychological distress of men and women with weak long-term ties to both work and family life. This may support the CAD framework in that disadvantaged origins and poor health in early life set men and women onto particular work-family biographical trajectories that led to further psychological distress in mid-life. The importance of early life factors may also suggest that socioeconomic or health selection played a strong role with poor mental health early in the life course 
leading to risky work-family biographies as well as continued psychological distress in mid-life, although previous work has shown reverse causation did not explain the poor health in midlife of women who spent long periods of the life course out of employment to look after the home in the 1946 cohort (McMunn, Bartley et al., 2006).

\section{Strengths and limitations}

This study was able to consider combined work and family biographies over a life course period spanning adolescence through midlife in relation to psychological distress at age 42/43, and to account for both early life predictors of work-family trajectories and adult mental health, and psychosocial and economic mediators in adulthood. We were also able to examine these associations in both women and men and to compare them across three British birth cohorts spanning a period of social change in work and family patterns. However, measuring and interpreting difference across cohorts is challenging. While the 1958 and 1970 British birth cohorts are designed to be comparable, often using identical measures, different measures are sometimes used in the 1946 cohort, including the measure of psychological health at age 43. A project to harmonise these measures across the three cohorts is currently underway (Ploubidis, 2019). In the meantime, this study sought to minimise the effects of these differences by deriving a relative measure of poor psychological health - the top quintile within each cohort. In addition, while we have minimised the effects of missing data through the use of multiple imputation techniques, all longitudinal cohort studies suffer from differential attrition such that disadvantaged and unhealthy cohort members are less likely to remain at age $42 / 43$. This may lead to more conservative estimates of association.

We have noted that the use of MCSA to characterise transitions and durations of spells of employment and family life is a novel contribution made by this work in the sense that its use better captures the complexity of the lived experience of the life course. However, using such a vast range of information - multiple states of employment, partnership and parenthood across a quarter century in three cohorts - as a risk factor for later poor health does raise complexities of interpretation which are worth discussing here for the benefit of future work in this area. While we have been able to illustrate a higher probability of psychological distress in mid-life for certain work-family biographies, the use of complex life course biographies makes it difficult to distinguish which particular aspect of these biographies may be driving the associations seen. For example, we were able to identify a greater probability of psychological distress for life courses characterised by non-employment and early family formation, but we are not able to test whether one of these domains was more strongly linked with later distress than the other or whether each is independently, equally important. Similarly, we are able to comment on the extent that early life circumstances attenuated our associations but not whether this attenuation was primarily working through employment, partnership or parenthood, or all three equally. While adopting a methodology that seeks to emulate an experimental approach can be criticised as artificially atomising the life course, a design which is better able to pinpoint potential causal mechanisms in relation to poor health is likely to yield more interpretable results. MCSA is an ideal method for characterising life courses; however, when it comes to linking those life courses with health outcomes, it may be better suited to hypothesis generation which raises the question of whether the time and labour intensity often required to conduct MCSA in life course data is justified.

\section{Conclusion}

This study suggests that women who made early transitions to parenthood, and men and women with weak ties to both work and family, appear to be particularly prone to mid-life mental health problems, with adolescent mental health playing an important role in setting young people onto trajectories of disadvantage in their work and family lives. This work has also shown that these life courses are becoming more strongly associated with psychological distress across cohorts as early parenthood and weak ties to employment become less normative. Teen pregnancy rates are declining rapidly in both the UK and the US (Livingston \& Thomas, 2019; Office for National Statistics, 2016); however, results here suggest the importance of targeting support for those who enter parenthood early, but also those excluded from both work and family support. The key role played by adolescent mental health in subsequent exclusion from employment and family life in the cohorts studied here suggests that current efforts by the UK government (NHS, 2019) may have longer-term benefits for employment, productivity and family life as well.

\section{Acknowledgements}

This work was funded by a European Research Council Starting Grant awarded to AM (No. (ERC-2011-StG_201011240). AM, RL and AS are also supported by the UK Economic and Social Research Council International Centre for Lifecourse Studies in Society and Health (ICLS) [grant number ES/J019119/1].

\section{Appendix A. Supplementary data}

Supplementary material related to this article can be found, in the online version, at doi:https://doi.org/10.1016/j.alcr.2021.100429.

\section{References}

Abbot, A., \& Tsay, A. (2000). Sequence analysis and optimal matching methods in sociology: Review and prospect. Sociological Methods \& Research, 29(1), 3-33.

Argyrous, G., Craig, L., \& Rahman, S. (2017). The effect of a first born child on work and childcare time allocation: pre-post analysis of Australian couples. Social Indictors Research, 131(2), 831-851.

Artazcoz, L., Benach, J., Borrell, C., \& Cortes, I. (2004). Unemployment and mental health: Understanding the interactions among gender, family roles, and social class. American Journal of Public Health, 94(1), 82-88.

Barban, N., \& Billari, Francesco C. (2012). Classifying life course trajectories: A comparison of latent class and sequence analysis. Applied Statistics, 61(5), 1-20.

Bartley, M. (2004). Health inequality: An introduction to theories, concepts and methods. Cambridge: Polity Press, 2004.

Beck-Gernsheim, E. (2002). Reinventing the family: In search of new lifestyles. Oxford: Blackwell.

Biello, B., Katie, H. L. S., \& Kershaw, T. (2010). Effect of teenage parenthood on mental health trajectories: Does sex matter? American Journal of Epidemiology, 172(3), 279-287.

Blomgren, J., Martikainen, P., Grundy, E., \& Koskinen, S. (2012). Marital history 1971-91 and mortality 1991-2004 in England \& Wales and Finland. Journal of Epidemiology and Community Health, 66, 30-36.

Brewer, M., \& Nandi, A. (2014). Partnership dissolution: How does it affect income, employment and well-being?. ISER working paper 2014-30. Essex: Institute of Economic and Social Research.

Brockmann, H., \& Klein, T. (2004). Love and death in Germany: The marital biography and its effect on mortality. Journal of Marriage and the Family, 66, 567-581.

Chandola, T., \& Zhang, N. (2018). Re-employment, job quality, health and allostatic load biomarkers: Prospective evidence from the UK Household Longitudinal Study. International Journal of Epidemiology, 47(1), 47-57.

Clouston, S. A. P., Lawlor, A., \& Verdery, A. M. (2014). The role of partnership status on late-life physical function. Canadian Journal of Aging/La Revue canadienne du vieillissement, 33, 413-425.

Crieghton, C. (1999). The rise and decline of the 'male breadwinner family' in Britain. Cambridge Journal of Economics, 23, 519-541.

Crompton, R. (2006). Employment and the Family: the Reconfiguration of Work and Family Life in Contemporary Societies. Cambridge. https://doi.org/10.1017/ CBO9780511488962

Dannefer, D. (2003). Cumulative advantage/disadvantage and the life course: Crossfertilizing age and social science theory. The Journals of Gerontology Series B, Psychological Sciences and Social Sciences, 58(6), S-327-S337.

Dex, S., Ward, K., \& Joshi, H. (2006). Changes in women's occupations and occupational mobility over 25 years. London: Centre for Longitudinal Studies.

Di Gessa, G., Corna, L., Price, D., \& Glaser, K. (2020). Lifetime employment histories and their relationship with 10-year health trajectories in later life: Evidence from England. European Journal of Public Health, 30(4), 793-799.

Einiö, E., Nisén, J., \& Martikainen, P. (2015). Is young fatherhood causally related to midlife mortality? A sibling fixed-effect study in Finland. Journal of Epidemiology and Community Health, 69, 1077-1082. 
Elder, G. H., \& Johnson, M. K. (2002). Chapter 2 the life course and aging: Challenges, lessons, and new directions. In A. Settersten Richard, Jr. (Ed.), Invitation to the life course: Towards new understandings of later life. New York: Taylor \& Francis.

Engels, M., Weyers, S., Moebus, S., Jockel, K.-H., Erbel, R., Pesch, B., Behrens, T., Dragano, N., \& Wahrendorf, M. (2019). Gendered work-family trajectories and depression at older age. Aging \& Mental Health, 23(11), 1478-1486.

England, P., \& Kilbourne, B. S. (1990). Markets, marriages, and other mates: The problem of power. In R. O. Friedland, \& A. F. Robertson (Eds.), Beyond the market place: Rethinking economy and society. Transaction Publishers.

Ferri, E., Bynner, J., \& Wadsworth, M. (2003). Changing Britain, changing lives: Three generations at the turn of the century. London: Institute of Education.

Flint, E., Bartley, M., Shelton, N., \& Sacker, A. (2013). Do labour market status transitions predict changes in psychological well-being? Journal of Epidemiology and Community Health, 67(9), 796-802.

Folbre, N. (2008). Reforming care. Politics \& Society, 36, 373-387.

Frech, A., \& Damaske, S. (2012). The relationship between mothers' work pathways and physical and mental health. Journal of Health and Social Behavior, 53(4), 396-412. https://doi.org/10.1177/0022146512453929

Gauthier, J.-A., Widmer, E. D., Bucher, P., \& Notredame, C. (2013). Multichannel optimal matching: A multidimensional approach to sequence analysis. In R. Levy, \& E. D. Widmer (Eds.), Gendered life courses (pp. 245-264). Berlin: Lit Verlag.

Giddens, A. (1992). The transformation of intimacy: Sexuality, love and erotocism in modern societies. Stanford, CA: Stanford University Press.

Glynn, K., Maclean, H., Forte, T., \& Cohen, M. (2009). The association between role overload and women's mental health. Journal of Women's Health, 18(2), 217-223.

Goode, W. J. (1960). A theory of role strain (p. 25). American Sociological Review.

Gregg, P., \& Machin, S. (2013). IPR Policy Brief - What a drag: the chilling impact of unemployment on real wages. University of Bath.

Grzywacz Joseph, G., \& Marks, N. F. (2000). Reconceptualizing the work-family interface: An ecological perspective on the correlates of positive and negative spillover between work and family. Journal of Occupational Health Psychology, 5(1), $111-126$.

Grzywacz Joseph, G., Almeida, D. M., Daniel, A., \& McDonald, D. A. (2002). Work-family spillover and daily reports of work and family stress in the adult labor force. Family Relations, 51(1), 28-36.

Guralnik, J. M., Butterworth, S., Patel, K., Mishra, G., \& Kuh, D. (2009). Reduced midlife physical functioning among never married and childless men: Evidence from the 1946 British Birth Cohort Study. Aging Clinical and Experimental Research, 21, $174-181$.

Gustafsson, S., Marie, A. K., Lindqvist, A., \& Restrom, E. A. (2019). The (Not so) changing man: Dynamic gender stereotypes in Sweden. Frontiers in Psychology. https://doi org/10.3389/fpsyg.2019.00037

Halpin, B. (2013). Imputing sequence data: Extensions to initial and terminal gaps. Stata's mi. Limerick: University of Limerick.

Hardy, R., Lawlor, D. A., Black, S., Mishra, G. D., \& Kuh, D. (2009). Age at birth of firs child and coronary heart disease risk factors at age 53 years in men and women: British birth cohort study. Journal of Epidemioly \& Community Health, 63, 99-105.

Harkness, S., Borkowska, M., \& Pelikh, A. (2019). Employment pathways and occupational change after childbirth. UK Government Equalities Office.

Harrington, B., Frone, J. S., \& Lee, J. (2017). The new dad: The career-caregiving conflict. Boston: Boston College.

Henseke, G. (2018). Good jobs, good pay, better health? The effects of job quality on health among older European workers. The European Journal of Health Economics, 19, 59-73.

Hewitt, B., Baxter, J., \& Western, M. (2006). Family, work and health: The impact of marriage, parenthood and employment on self-reported health of Australian men and women. Journal of Sociology, 42(1), 61-78.

Huchet-Bodet, A., Albakri, M., \& Smith, N. (2019). Attitudes to equalities: The british socia attitudes survey 2017. London: NatCen Social Research.

Hughes, A., Kumari, M., McMunn, A., \& Bartley, M. (2017). Unemployment and inflammatory markers in England, Wales and Scotland, 1998-2012: Meta-analysis of results from 12 studies. Brain, Behaviour \& Immunity, 64, 91-102.

Hughes, A., McMunn, A., Bartley, M., \& Kumari, M. (2014). Elevated inflammatory biomarkers during unemployment: modification by age and country in the UK. Journal of Epidemiology and Community Health, 69(7). https://doi.org/10.1136/jech2014-204404

Jahoda, M. (1982). Employment and unemployment: A social-psychological analysis. CUP Archive.

Janzen, B. L., \& Muhajarine, N. (2003). Social role occupancy, gender, income adequacy, life stage and health: A longitudinal study of employed Canadian men and women. Social Science \& Medicine, 57(8), 1491-1503.

Johansson, G., Huang, Q., \& Lidfors, P. (2007). A life-span perspective on women's careers, health and well-being. Social Science \& Medicine, 65(4), 685-697.

Kan, M. Y., Sullivan, O., \& Gershuny, J. (2011). Gender Convergence in Domestic Work Discerning the Effects of Interactional and Institutional Barriers from Large-scale Data. Sociology, 45(2), 234-251.

Kendig, H., \& Nazroo, J. (2016). Life Course Influences on Inequalities in Later Life: Comparative Perspectives. Journal of Population Ageing, 9(1-2), 1-7.

Kiernan, K. E., \& Diamond, I. (1983). The age at which childbearing starts - a longitudinal study. Population Studies, 37(3), 363-380.

Kiernan, K. E., \& Eldridge, S. M. (1987). Age at marriage: inter and intra cohort variations. The British Journal of Sociology, 38, 44-65.

Kinnunen, U., Taru, F., Sabine, G., \& Lea, P. (2006). Types of work-family interface: Wellbeing correlates of negative and positive spillover between work and family. Scandinavian Journal of Psychology, 47(2), 149-162.
Klumb, P. L., \& Lampert, T. (2004). Women, work, and well-being 1950-2000: A review and methodological critique. Social Science \& Medicine, 58, 1007-1024.

Krieger, N., Chen, J. T., \& Selby, J. V. (1999). Comparing individual-based and household-based measures of social class to assess class inequalities in women's health: A methodological study of 684 US women. Journal of Epidemiology and Community Health, 53, 612-623.

Kuhhirt, M. (2012). Childbirth and the long-term division of labour within couples: How do substitution, bargaining power and norms affect parents' time allocation in West Germany? European Sociological Review, 28(5), 565-582.

Kuntsche, S., Knibbe, R. A., \& Gmel, G. (2009). Social roles and alcohol consumption: A study of 10 industrialised countries. Social Science \& Medicine, 68(7), 1263-1270.

Lacey, R., Kumari, M., \& McMunn, A. (2013). Parental separation in childhood and adult inflammation: The importance of material and psychosocial pathways. Psychoneuroendocrinology, 38(11), 2476-2484. https://doi.org/10.1016/j psyneuen.2013.05.007

Lacey, R. E., Kumari, M., Sacker, A., \& McMunn, A. (2017a). Age at first birth and cardiovascular risk factors in the 1958 British birth cohort. Journal of Epidemiology and Community Health, 71, 691-698.

Lacey, R. E., Sacker, A., Bell, S., Kumari, M., Worts, D., McDonough, P., Kuh, D., \& McMunn, A. (2017b). Work-family life courses and BMI trajectories in three British birth cohorts. International Journal of Obesity, 41, 332-339.

Lacey, R. E., Sacker, A., Kumari, M., Worts, D., McDonough, P., Booker, C., et al. (2016b). Work-family life courses and markers of stress and inflammation in mid-life: evidence from the National Child Development Study. International Journal of Epidemiology, 45(4), 1247-1259.

Lacey, R. E., Stafford, M., Sacker, A., \& McMunn, A. (2016a). Work-family life courses and subjective wellbeing in the MRC national survey of health and development (the 1946 british birth cohort study). Journal of Population Ageing, 9, 69-89.

Lahelma, E., Arber, S., Kivela, K., \& Roos, E. (2002). Multiple roles and health among British and Finnish women: The influence of socioeconomic circumstances. Social Science \& Medicine, 54, 727-740.

Leupp, K. (2017). Depression, work and family roles, and the gendered life course. Journal of Health and Social Behavior, 58(4), 422-441.

Lindelow, M., Hardy, R., \& Rodgers, B. (1997). Development of a scale to measure symptoms of anxiety and depression in the general UK population: the psychiatric symptom frequency scale. Journal of Epidemiology and Community Health, 51(5), 549-557.

Livingston, G., \& Thomas, D. (2019). US Teen Birth Rate has fallen dramatically over time. Washington, D.C: Pew Research Centre.

Lund, R., Christensen, U., Nilsson, C. J., Kriegbaum, M., \& Rod, N. H. (2014). Stressful social relations and mortality: A prospective cohort study. Journal of Epidemiology and Community Health, 68, 720-727.

MacIndoe, H., \& Abbott, A. (2004). Sequence analysis and optimal matching techniques for social science data. In M. Hardy, \& A. Bryman (Eds.), Handbook of data analysis sage (pp. 387-406). Thousand Oaks, CA.

Marks, Stephen R. (1977). Multiple Roles and Role Strain: Some Notes on Human Energy, Time and Commitment. Sociological Review, 42(6).

McDonough, P., Worts, D., Booker, C., McMunn, A., \& Sacker, A. (2015). Cumulative disadvantage, employment-marriage, and health inequalities among American and British mothers. Advances in Life Course Research, 25, 49-66.

McLeod, J. L. (2012). The Meanings of Stress: Expanding the Stress Process Model. Society and Mental Health, 2(3), 172-186.

McMunn, A., Bird, L., Webb, E., \& Sacker, A. (2019). Gender divisions of paid and unpaid work in contemporary UK couples. Work Employment \& Society, 25(2), 274-291.

McMunn, A., Lacey, R., Worts, D., McDonough, P., Kumari, M. \& Sacker, A. (2016). Work-family life courses and metabolic markers in mid-life: Evidence from the British National Child Development Study. Journal of Epidemiology and Community Health, 70, 481-487.

McMunn, A., Lacey, R., Worts, D., McDonough, P., Stafford, M., Booker, C., ... Sacker, A. (2015). De-standardization and gender convergence in work-Family life courses in Great Britain: A multi-channel sequence analysis. Advances in Life Course Research, 26, 60-75.

McMunn, A., Bartley, M., Hardy, R., \& Kuh, D. (2006a). Life course social roles and women's health in mid-life: Causation or selection? Journal of Epidemiology and Community Health, 60, 484-489.

McMunn, A., Melanie, B., \& Diana, K. (2006b). Life course social roles, women's health in mid-life and agency as quality. Social Science \& Medicine, 63(6), 1561-1572.

NHS. (2019). Mental health implementation plan 2019/20-2023/24. July https://www.lo ngtermplan.nhs.uk/wp-content/uploads/2019/07/nhs-mental-health-implementat ion-plan-2019-20-2023-24.pdf.

Nordenmark, M. (2004). Multiple social roles and well-being: A longitudinal test of role stress theory and the role expansion theory. Acta Sociologica, 47, 115-126.

O'Rand, P. A. (2009). Cumulative processes in the life course. In G. H. Elder, Jr., \& J. Giele (Eds.), The craft of life course research (pp. 121-139). New York, NY: The Guildford Press.

Office for National Statistics. (2016). Live births women aged 'Under 18' and 'Under 20'.

Office for National Statistics. (2013). Women in the labour market: 2013.

Pachana, N. A., McLaughlin, D., Leung, J., McKenzie, S. J., \& Dobson, A. (2011). The effect of having a partner on activities of daily living in men and women aged 82-87 years. Maturitas, 68, 286-290.

Paul, K. I., \& Batinic, B. (2009). The need for work: Jahoda's latent functions of employment in a representative sample of the German population. Journal of Organizational Behavior. https://doi.org/10.1002/job.622

Perelli-Harris, B., Berrington, A., Gassen, N. S., Galezewska, P., \& Holland, J. A. (2017). The rise in divorce and cohabitation: Is there a link? Population and Development Review, 43(2), 303-329. 
Ploubidis, G. B. (2019). Unlocking the potential of mental health measures in the British birth cohorts. London: CLOSER blog. https://www.closer.ac.uk/news-opinion/blog/unl ocking-potential-mental-health-measures-british-birth-cohorts/.

Pollock, G. (2007). Holistic trajectories: A study of combined employment, housing and family careers by using multiple-sequence analysis. Journal of the Royal Statistical Society Series A, 170(1), 167-183.

Power, C., \& Elliott, J. (2005). Cohort profile: 1958 British birth cohort. International Journal of Epidemiology, 35, 34-41.

Richards, M., \& Abbott, R. (2009). Childhood mental health and life chances in Post-War Britain. London: Sainsbury Centre for Mental Health.

Roberts, E. (1995). Women and families: An oral history, 1940-1970. Oxford: Blackwell.

Robles, T. F., Slatcher, R. B., Trombello, J. M. \& McGinn, M. M. (2014). Marital quality and health: A meta-analytic review. Psychological Bulletin, 140(1). https://doi.org/ $10.1037 / \mathrm{a} 0031859$

Rutter, M. (1970). Education, health and behaviour. Harlow: Longman.

Sabbath Erica, L., Guevara, I. M., Glymour, M., \& Berkman, L. F. (2015). Use of life course work-Family profiles to predict mortality risk among US women. American Journal of Public Health, 105(4), e96-e102.

Schober, P. S. (2013). The parenthood effect on gender inequality: Explaining the change in paid and domestic work when british couples become parents. European Sociological Review, 29(1), 74-85.

Schoon, I. (2009). Changing educational aspirations in three UK cohorts: The role of gender, parental education and encouragement. International Society for the Study of Behavioural Development (ISSBD) Bulletin, 55(1), 14-18.

Scott, J. (2006). Family and gender roles: How attitudes are changing. Cambridge: GeNet Working Paper No. 21.

Stone, J., Evandrou, M., Falkingham, J., \& Vlachantoni, A. (2015). Women's economic activity trajectories over the life course: implications for the self-rated health of women aged 64+ in England. Journal of Epidemioly \& Community Health, 69, 873-879.

Strandh, M., Hammarstrom, A., Nilsson, K., Nordenmark, M., \& Russel, H. (2012). Unemployment, gender and mental health: The role of the gender regime. Sociology of Health \& Illness. https://doi.org/10.1111/j.1467-9566.2012.01517.x

Thoits, P. A. (1991). On merging identity theory and stress research. Social Psychology Quarterly, 54, 101-112.

Tinkler, P., Spencer, S., \& Langhamer, C. (Eds.). (2017). Women in fifties Britain a New look. Routledge.

Tosi, M., \& Grundy, E. (2019). Work-family lifecourses and later-life health in the United Kingdom. Ageing and Society, 1-27. https://doi.org/10.1017/S0144686X19001752
University of London, Institute of Education, \& Centre for Longitudinal Studies. (2008). National child development study: Sweep 6, 1999-2000 [data collection] (2nd edition, p. 5578). SN: Joint Centre for Longitudinal Research, [original data producer(s)]. Joint Centre for Longitudinal Research. https://doi.org/10.5255/UKDA-SN-5578-1.

University of London, Institute of Education, \& Centre for Longitudinal Studies. (2016). 1970 British cohort study: Forty-two-Year follow-up, 2012 [data collection] (2nd edition, p. 7473). SN: UK Data Service. https://doi.org/10.5255/UKDA-SN-7473-2.

van Hedel, K., Mejia-Guevara, I., Avendano, M., Sabbath, E. L., Berkman, L. F., Mackenbach, J. P., et al. (2016). Work-Family trajectories and the higher cardiovascular risk of american women relative to women in 13 european countries. Amerian Journal of Public Health, 106(8), 1449-1456.

Verbrugge, Lois M. (1983). Multiple Roles and Physical Health of Women and Men. Journal of Health and Social Behavior, 24(1), 16-30.

Von Hippel, P. (2007). Regression with Missing Ys: An Improved Strategy for Analyzing Multiply Imputed Data. Sociological Methodology, 37, 83-117.

Wadsworth, M., Kuh, D., Richards, M., \& Hardy, R. (2006). Cohort profile: The 1946 national birth cohort (MRC national survey of health and development). International Journal of Epidemiology, 35(1), 49-54.

Wahrendorf, M. (2015). Previous employment histories and quality of life in older ages: Sequence analyses using SHARELIFE. Ageing and Society, 35(09), 1928-1959.

Waite, L., \& Maggie, G. (2001). The case for marriage: Why married people are happier, healthier, and better off financially. Broadway Books.

Wiggins, R. D., Erzberger, C., Hyde, M., Higgs, P., \& Blane, D. (2007). Optimal matching analysis using ideal types to describe the lifecourse: An illustration of how histories of work, partnerships and housing relate to quality of life in early old age. International Journal of Social Research Methodology, 10(4), 259-278.

Williams, K. (2003). Has the future of marriage arrived? A contemporary examination of gender, marriage, and psychological wellbeing. Journal of Health and Social Behavior, 44, 470-487.

Woods, N., McMunn, A., Webb, E., \& Stafford, M. (2019). Marriage and physical capability at mid to later life in England and the USA. PloS One. https://doi.org/ 10.1371/journal.pone.0209388

Worts, D., Sacker, A., McMunn, A., \& McDonough, P. (2013). Individualization, opportunity and jeopardy in American women's work and family lives: A multi-state sequence analysis. Advances in Life Course Research, 18(4), 296-318.

Xue, B., Tinkler, P., Elliott, P. Z., Jane, \& Shepherd, P. (2006). Cohort profile: 1970 british birth cohort. International Journal of Epidemiology, 35, 836-843.

Yan, X.-Y., Huang, S.-M., Huang, C.-Q., Wu, W.-H., \& Qin, Y. (2011). Marital status and risk for late life depression: A meta-analysis of the published literature. The Journal of International Medical Research, 39(4), 1142-1154. 